\title{
Case effects in letter-name matching: A partial replication
}

\author{
DAVID B. BOLES \\ University of Oregon, Eugene, Oregon \\ and \\ JOSEPH B. HELLIGE \\ University of Southern California, Los Angeles, California
}

\begin{abstract}
When same-case letter pairs are to be physically matched as "same" or "different," reaction times (RTs) are generally shorter for "same" responses. The advantage in RT increases when such pairs are intermixed in blocks of trials also containing mixed-case pairs to be matched for name identity. These results have been interpreted as supportive of a two-code hypothesis of letter matching: In pure blocks of same-case pairs, a visual or physical code underlies letter matching, whereas in intermixed blocks, a phonetic or name code must be used for all "different" judgments. The theory predicts, however, that there should be little discrepancy in RT for same-case and mixed-case "different" pairs in intermixed blocks. Here a partial replication of Hellige and Webster (1981) is reported, showing that in fact there is a reliable discrepancy. This outcome poses problems for the two-code hypothesis, although it may be consistent with a "generation" hypothesis of letter matching.
\end{abstract}

When two same-case letters are presented simultaneously or nearly simultaneously and matched for physical identity, reaction times (RTs) to "same" pairs (e.g., AA) are somewhat faster than RTs to "different" pairs (e.g., AB), the former typically showing a mean RT advantage of perhaps $15-50 \mathrm{msec}$ (Bagnara, Boles, Simion, \& Umiltà, 1982; Cohen, 1973; Posner \& Boies, 1971; Posner \& Mitchell, 1967), and even a zero advantage when asymmetric letters are used and different pairs are constructed for minimal visual similarity (Bagnara, Boles, Simion, \& Umiltà, Note 1). However, when such pairs are intermixed with mixed-case pairs (e.g., $\mathrm{Aa}, \mathrm{Ab}$ ) and matched for nominal identity, the typical RT difference between "same" and "different" same-case pairs increases, then being on the order of 50-100 msec (Boles, 1981; Cole \& Haber, 1980; Dainoff, 1970; Hellige \& Webster, 1981; Posner, Boies, Eichelman, \& Taylor, 1969; Posner \& Mitchell, 1967).

This interaction between the types of same-case letter pair employed ("same" vs. "different") and the manner in which they are blocked (pure blocks vs. intermixed with mixed-case pairs) has commonly been interpreted as being supportive of a two-code model of letter matching (Posner, 1978). By this account, similar RTs for the pair types should be produced in pure blocks, since a visual or physical code is used to assess

This research was supported by National Institute of General Medical Science Grant 5 T0 1 GM0 2165. Reprint requests should be addressed to David B. Boles, Department of Psychology, University of Illinois, Champaign, Illinois 61820. identity for both types. But when the pairs are presented in intermixed blocks, the visual code is sufficient to match only same-case "same" pairs (e.g., AA), and cannot be used to produce a "different" judgment, since some "same" pairs are not physically identical (e.g., Aa). For such pairs, for which the physical code does not produce a fast "same" response, the two-code model states that a name or phonetic code is used. Since this presumably requires more processing time, an increase is observed in the RT disparity between "same" and "different" same-case pairs, compared with that obtained in pure blocks.

An important prediction of the two-code view is that, in intermixed blocks, RTs for same-case and mixed-case "different" pairs should be similar. According to the above account, both such pairs should be matched using the name code, with the result that equally long RTs should be observed. Yet surprisingly, there appear to be few tests of this assumption in the literature, with most researchers preferring to combine the types into one "different" condition for purposes of data summary and analysis (e.g., Boles, 1981; Posner, 1978; Posner \& Mitchell, 1967). In defense of this practice, until recently those few papers that have reported the conditions separately have found rather similar RTs across the conditions (Cole \& Haber, 1980; Dainoff, 1970; Posner et al., 1969).

However, Hellige and Webster (1981) found a substantial disparity. In their experiment, which employed intermixed blocks, same-case "different" pairs were matched about $50 \mathrm{msec}$ more quickly than mixed-case 
"different" pairs. Although this was reduced relative to the analogous "same"-pair disparity (about $90 \mathrm{msec}$ ), the nontrivial difference between mixed-case and samecase pairs calls into question the view that the two types of "different" pairs are matched similarly by subjects.

The primary purpose of this paper is to reexamine data originally reported by Boles (1981) in light of the findings of Hellige and Webster (1981). Boles's original report emphasized visual-field differences in lettermatching latency, and it collapsed mixed-case and samecase "different" pairs together in combined analyses. However, the data were collected and retained in a form allowing this division to be made. In light of the potential importance of the finding by Hellige and Webster, since it reflects on the view that mixed-case and same-case "different" pairs can be matched similarly, more detailed analyses of the relevant experiments are now reported.

Secondarily, an analysis of the data relative to an additional finding of Hellige and Webster (1981) is also reported. They found a three-way interaction of same case/mixed case $x$ "same"/"different" matches $x$ left/ right visual fields. This interaction occurred because on left-visual-field/right-hemisphere (LVF-RH) trials, the same-case versus mixed-case effect was as large for different-name letter pairs as for same-name letter pairs. In contrast, on right-visual-field/left-hemisphere trials (RVF-LH), the same-case versus mixed-case effect was smaller for different-name letter pairs than for samename pairs. This interaction can also be described in terms of visual-field asymmetries within various conditions. Specifically, it was found that (1) "same" pairs, both mixed case and same case, produced a LVF-RH advantage in RT, and (2) "different" pairs produced little field difference when same case, but a RVF-LH advantage when mixed case. The potential importance of the interaction is that it supports hemispheric differences in letter matching, and so could be of some use in understanding the processes involved. Although Boles (1981) reported generally inconsistent visual-field effects, again the "different"-pair data were not broken down into same-case versus mixed-case pairs, so this interaction was not assessed.

\section{METHOD}

The method used has been reported elsewhere (Boles, 1981) and will not be repeated in detail here. Briefly, however, letter pairs were presented on a CRT controlled by computer, with the pairs oriented horizontally and to one side or the other of a central fixation point. Subjects responded by pressing RT keys for "same" and "different" judgments.

\section{RESULTS}

The experiments to be reanalyzed are those in which mixed-case and same-case pairs were intermixed, comprising Experiments 1, 2, 3, 4, and 8 of the earlier report. They are renumbered here as Experiments 1, 2, 3,4 , and 5 , respectively.

\section{Case Effects in "Different" Pairs}

Table 1 shows the same-case advantage in RT for "different" pairs over the five experiments. As can be seen, a significant advantage (by one-tailed test) was found in each, with a mean magnitude of $24 \mathrm{msec}$. By comparison, the mean same-case advantage for "same" pairs, deducible from data presented in the earlier report, was $89 \mathrm{msec}$. Thus, the primary finding of Hellige and Webster (1981) is also apparent in these results, being a nontrivial same-case advantage for "different" pairs, which nevertheless is smaller than that for "same" pairs. In percent errors, no such advantage was found here for "different" pairs, the mean same-case advantage being only $0.4 \%$.

Table 1

Case Effects in "Different" Pairs

\begin{tabular}{ccccc}
\hline & \multicolumn{4}{c}{ RT (in Milliseconds) } \\
\cline { 2 - 5 } Experiment & $\begin{array}{c}\text { Mixed } \\
\text { Case }\end{array}$ & $\begin{array}{c}\text { Same } \\
\text { Case }\end{array}$ & Difference & $\mathrm{p}$ \\
\hline 1 & 696 & 668 & +28 & .0002 \\
2 & 651 & 627 & +24 & .001 \\
3 & 620 & 606 & +14 & .03 \\
4 & 719 & 693 & +26 & .01 \\
5 & 703 & 675 & +28 & .00008 \\
\hline
\end{tabular}

Note-Mean difference value $=+24 \mathrm{msec}$.

Table 2

The Three-Way Interaction in RT

\begin{tabular}{|c|c|c|c|c|c|c|c|c|c|c|c|}
\hline \multirow{4}{*}{$\begin{array}{c}\text { Experi- } \\
\text { ment }\end{array}$} & \multicolumn{8}{|c|}{ Match } & \multirow[b]{4}{*}{ Interaction } & \multirow[b]{4}{*}{$\mathrm{p}$} & \multirow[b]{4}{*}{$\mathbf{z}$} \\
\hline & \multicolumn{4}{|c|}{ "Same" } & \multicolumn{4}{|c|}{ "Different" } & & & \\
\hline & \multicolumn{2}{|c|}{ Same Case } & \multicolumn{2}{|c|}{ Mixed Case } & \multicolumn{2}{|c|}{ Same Case } & \multicolumn{2}{|c|}{ Mixed Case } & & & \\
\hline & LVF & RVF & LVF & RVF & LVF & RVF & LVF & RVF & & & \\
\hline $\begin{array}{l}1 \\
2 \\
3 \\
4 \\
5\end{array}$ & $\begin{array}{l}583 \\
537 \\
517 \\
636 \\
617\end{array}$ & $\begin{array}{l}555 \\
536 \\
501 \\
616 \\
622\end{array}$ & $\begin{array}{l}672 \\
628 \\
613 \\
709 \\
693\end{array}$ & $\begin{array}{l}683 \\
618 \\
600 \\
703 \\
688\end{array}$ & $\begin{array}{l}675 \\
632 \\
608 \\
700 \\
674\end{array}$ & $\begin{array}{l}661 \\
621 \\
603 \\
686 \\
676\end{array}$ & $\begin{array}{l}691 \\
656 \\
620 \\
729 \\
703\end{array}$ & $\begin{array}{l}701 \\
645 \\
619 \\
710 \\
703\end{array}$ & $\begin{array}{r}+15 \\
-9 \\
-1 \\
+19 \\
-8\end{array}$ & $\begin{array}{l}.17 \\
.66 \\
.53 \\
.19 \\
.60\end{array}$ & $\begin{array}{l}+.95 \\
-.41 \\
-.07 \\
+.89 \\
-.26\end{array}$ \\
\hline Mean & 578 & 566 & 663 & 658 & 658 & 649 & 680 & 676 & +2 & & \\
\hline
\end{tabular}

Note $-p^{\prime}=+.31 ; z^{\prime}=+.49$. 


\section{Three-Way Interaction}

Table 2 presents a metaanalysis of the mixed case/ same case $x$ "same"/"different" match $x$ left/right visual field interaction in RT across the five experiments. The method used was the "Stouffer" method (Rosenthal, 1978), in which individual probabilities are converted to $\mathrm{z}$ scores, and an overall probability is assessed by summing the $\mathrm{z}$ scores, dividing by the square root of the number of studies, and converting the resultant $\mathrm{z}$ score (here called $z^{\prime}$ ) back to a probability (here called p').

As can be seen, in none of the experiments was there a significant effect, and the overall $\mathrm{z}^{\prime}$ of +.49 was also nonsignificant $\left(\mathrm{p}^{\prime}=.31\right)$. And no such effect was found in a metaanalysis of the percent-error data $\left(\mathrm{z}^{\prime}=-.24\right.$, $\left.\mathrm{p}^{\prime}=.59\right)$. Thus, the secondary finding of Hellige and Webster (1981), a three-way interaction, was not replicated here.

\section{DISCUSSION}

The primary finding of Hellige and Webster (1981) was repeated in the present results, being a same-case over mixed-case RT advantage for "different" letter pairs. As a reasonably robust effect (of about 50- and 24-msec magnitude in the two studies, respectively), the difference raises the question of whether the pair types are necessarily matched by the same code in intermixed blocks (Posner, 1978). To be sure, the disparity between "same" pairs is larger (Boles, 1981; Cole \& Haber, 1980;Dainoff, 1970; Hellige \& Webster, 1981; Posner et al., 1969; Posner \& Mitchell, 1967), and this is a phenomenon ultimately requiring explanation, but the finding of RT nonequivalence for "different" pairs does raise questions about the assumption that both types are matched using a name or phonetic code. If they were, the resulting RTs would be expected to be more nearly the same.

If not by a name code, how are letters matched as "different" in intermixed blocks? One possibility comes from the work of Boles and Eveland (1983). They reported converging evidence that mixed-case letter pairs are not matched using a name or phonetic code, but rather may be matched following a generation process that evokes visually represented opposite cases of the letters. Thus, a "same" match can be supported by visual equivalence between the letters actually presented (e.g., Aa) and those that are internally generated $(\mathrm{aA})$. If so, then mixedcase "different" pairs (e.g., Ae) could produce relatively long RTs in intermixed blocks, since, like the letters actually shown, the generated letters are also of mixed case $(\mathrm{aE})$. In same-case "different" pairs, by contrast, the presented letters (e.g., AB) are always in the opposite case from the generated letters (ab), producing less chance for confusion and thus shorter RTs. According to this model, then, the mixed-case/same-case disparity arises from identical processes underlying the two types of matches, but derives from differing visual confusion between presented and generated letters. In pure blocks, of course, the disparity between pair types would be greater, since then the same-case pairs can always be matched by a direct visual comparison, whereas mixed-case pairs would continue to require the generation process.

Although these experiments have partially replicated the findings of Hellige and Webster (1981), a major difference in outcome is that, here, a three-way interaction was not found among case conditions, match, and visual field. We have no explanation for this discrepancy. However, there is some evi- dence that variations of input parameters, response requirements, and precise task demands influence visual-field asymmetries (e.g., Hellige, 1983; Sergent, 1983), and we can point to a number of procedural differences between the studies that could ultimately prove important. For example, Hellige and Webster used a set of eight letters, paired vertically, presented white-on-dark, with controlled size and eccentricity, and 10-msec duration. Boles (1981) used sets of four letters, paired horizontally, presented green- or blue-on-dark (depending on the CRT phosphor), with subject-selected distance (and thus size and eccentricity), and 150-msec duration. Hellige and Webster used response keys located on left and right, gave subjects 12 practice trials and 640 experimental trials, did not give feedback, and employed a $6.0-\mathrm{sec}$ interval between a response and the reappearance of the fixation dot. Boles used response keys located nearer and farther, gave subjects from 128 to 832 practice trials and 384 to 512 experimental trials (depending on the experiment), gave feedback, and employed a 1.7-sec interval between response and the reappearance of the fixation dot. It remains to be seen, of course, whether any of these methodological differences can account for the discrepancy in findings, but they may serve as a point of departure in any such investigation.

\section{REFERENCE NOTE}

1. Bagnara, S., Boles, D. B., Simion, F., \& Umiltà, C. Symmetry and similarity effects in the comparison of visual patterns. Manuscript in preparation, 1983.

\section{REFERENCES}

Bagnara, S., Boles, D. B., Simion, F., \& Umiltì, C. Can an analytic/holistic dichotomy explain hemispheric asymmetries? Cortex, 1982, 18, 67-78.

Boles, D. B. Variability in letter-matching asymmetry. Perception \& Psychophysics, 1981, 29, 285-288.

Boles, D. B., \& Eveland, D. C. Visual and phonetic codes, and the process of generation in letter matching. Journal of Experimental Psychology: Human Perception and Performance, 1983, 9, 657-674.

Cohen, G. Hemispheric differences in serial versus parallel processing. Journal of Experimental Psychology, 1973, 97, 349-356.

Cole, R. A., \& HABER, R. N. Reaction time to letter name or letter case. Acta Psychologica, 1980, 4, 281-285.

Dainofr, M. J. Time course of visual and auditory encoding. Journal of Experimental Psychology, 1970, 86, 214-224.

HeLlige, J. B. (Ed.). Cerebral hemisphere asymmetry: Method, theory, and application. New York: Praeger, 1983.

Hellige, J. B., \& Webster, R. Case effects in letter-name matching: A qualitative visual field difference. Bulletin of the Psychonomic Society, 1981, 17, 179-182.

Posner, M. I. Chronometric explorations of mind. Hillsdale, N.J: Erlbaum, 1978.

Posner, M. I., \& Boies, S. J. Components of attention. Psychological Review, 1971, 78, 391-408.

Posner, M. I., Boles, S. J., Eichelman, W. H., \& Taylor, R. L. Retention of visual and name codes of single letters. Journal of Experimental Psychology Monograph, 1969, 79(1, Pt. 2).

Posner, M. I., \& Mitchell, R. F. Chronometric analysis of classification. Psychological Review, 1967, 74, 392-409.

Rosenthal, R. Combining results of independent studies. Psychological Bulletin, 1978, 85, 185-193.

Sergent, J. Role of the input in visual hemispheric asymmetries. Psychological Bulletin, 1983, 93, 481-512.

(Manuscript received for publication September 5, 1983.) 